\title{
Invited review: Ruminating conscientiously: Scientific and socio-ethical challenges for US dairy production
}

\author{
C. C. Croney ${ }^{* 1}$ and R. Anthony† \\ *Department of Veterinary Preventive Medicine, College of Veterinary Medicine, The Ohio State University, Columbus 43210 \\ †Department of Philosophy, University of Alaska-Anchorage, Anchorage 99508
}

\begin{abstract}
Despite the predominantly positive depictions of dairy production, public concern about farm animal production practices in the United States is currently higher than at any point in recent history. Many standard industry practices, including some used by the US dairy industries, are increasingly challenged not just on scientific grounds, but also on ethical grounds. Concerns include the environmental impacts and sustainability of modern farm animal production practices, food safety and security, and the increasingly complex issue of animal welfare. As the impetus increases to achieve broad stakeholder engagement in discussions of US food policy, understanding and addressing the ethical concerns associated with contemporary dairy production is critically important to ensure the industry's autonomy and long-term viability. Animal welfare assessment or accountability tools such as the Ethical Matrix or Campbell's Ethics Assessment Process can provide a structured, transparent method of making appropriate ethical choices about the care and welfare of farm animals that are also scientifically grounded.
\end{abstract}

Key words: animal ethics, assessment, dairy cattle, animal welfare

\section{INTRODUCTION}

Compared with other animal industries, the welfare of animals used in modern dairy production may appear to some to be relatively unproblematic. This perception may be partially reinforced by bucolic scenes of pastured cattle grazing near public roadways, which in turn may foster the belief that all dairy cattle are reared in this manner. Such positive imagery is perpetuated by the ubiquitous and tremendously effective "Happy Cow" commercials developed by the California Milk Advisory Board, although these have been criticized by some as

Received July 15, 2010.

Accepted October 14, 2010.

${ }^{1}$ Corresponding author: croney.1@osu.edu being largely misrepresentative of modern dairy production (Glenn, 2004; Croney and Reynnells, 2008).

Despite the predominantly positive depictions of dairy production, public scrutiny of US farm animal production is higher than at any point in recent history and consequently, many standard industry practices, including several used by the US dairy industry, are increasingly challenged on ethical grounds. Concerns range from those related to environmental impact and sustainability of many of the industry's practices, to that of food safety and security and the increasingly complex issue of animal welfare. These issues were discussed and debated at the recent Council of Agricultural Science and Technology (CAST)-USDA Food-Animal Agriculture Symposium titled "Sustaining Animal Agriculture: Balancing Bioethical, Economic, and Social Issues" held June 8-10, 2010.

It becomes important, therefore, to note that like all of the animal industries, the dairy industries still have significant welfare issues to address despite myriad improvements over the last few decades. Furthermore, as consumers begin to use animal welfare to indicate other important product attributes, such as safety and healthfulness (Harper and Makatouni, 2002), it is imperative for producers to avoid even the appearance of complacency relative to the scientific and socio-ethical concerns associated with modern dairy production. As the impetus increases to broadly engage stakeholders in general discussions of US food policy and as consumers become more interested in learning about the production narrative of their food, understanding and addressing the ethical concerns pertinent to contemporary dairy production becomes an essential step in ensuring the industry's long-term viability.

\section{ETHICS AND ANIMAL WELFARE}

Addressing the ethical concerns that are increasingly raised about modern animal agricultural practices requires a basic understanding of some key concepts. First, ethics is intimately connected to values. Broadly, values are ideas that direct our actions, give meaning to our lives, and guide us to be "good" or to live well with 
others. Our values inform standards of right and wrong as established by a moral community and serve to regulate and limit the behavior of its members (Thompson, 1998).

In a pluralistic society, it can be difficult to agree upon such values and standards of conduct as they apply to how we think about and should interact with other human members of the moral community. Predictably, reaching consensus on universal principles governing the "right" treatment of animals can become even more problematic. As one prominent philosopher, Annette Baier (1986), writes, "a complete moral philosophy would tell us how and why we should act and feel toward others in relationships of shifting and varying power asymmetry and shifting varying intimacy."

For those who aspire toward a more complete animal ethics, Baier's (1986) comments provide an interesting point on which to ruminate. Animals as moral subjects are vulnerable members of our moral community. And although human beings may enjoy a different moral status than animals, we have also developed somewhat nuanced relationships with certain animals, such as those used for companionship, farming, or research. These relationships may entail particular responsibilities of care (Anthony, 2003) or caretaking (Haynes, 2008). Failure to perform these responsibilities has not always been regarded consistently as morally problematic by the public or members of the food industries. Unsurprisingly, therefore, one of the most contentious issues that developed nations are currently facing is reaching consensus about our moral obligations toward the animals that we employ for human benefit, and what such obligations mean for their care and welfare.

Any working definition of animal welfare ethics, therefore, must not only take into consideration animals' relative vulnerability, but must also help to articulate our direct and indirect responsibilities toward animals both generally and in specific situations. However, it is inadequate and impractical to simply construct a list of dos and don'ts for those who interact with or care for animals. Some justification for our actions is necessary. This should be informed not only by the practicalities of animal use (e.g., food animal production systems), but also by ethically defensible reasons for acting in certain ways. Such ethical standards of conduct and values associated with animal agriculture should be based on theoretical ethics, aspects of our common morality, acknowledgment of the vulnerability of animals in our charge, and empirical research, lest animal welfare ethics become arbitrary.

As the impetus increases to ensure that farm animal production is both scientifically grounded and ethically responsible, debates about animal welfare will continue to require understanding of and accounting for the in- terests and of all the various stakeholders and reasons that motivate conflicts of interest between them. This requires an organized thought process that broadly considers the implications of animal care and welfare decisions (Croney and Anthony, 2010). An ethical accounting or assessment process (to be discussed later) can facilitate this process. First, however, it is essential to clarify the general nature of concerns related to animal welfare, as well as the specific concerns pertaining to modern dairy production.

\section{WHAT ARE THE CONCERNS ABOUT ANIMAL WELFARE AND WHAT ARE THEIR BASES?}

Animal welfare concerns are fundamentally about animal quality of life and are grounded in the belief that humans have a moral responsibility to maintain an acceptable standard of life care and welfare for all animals, including those used for food. More specifically, animal welfare concerns revolve around the issues of pain and suffering (or affective experience), the capacity for the animal to function well, and opportunities to exhibit behaviors commensurate with the animal's adaptations (Fraser et al., 1997). These concerns are expressed by the Five Freedoms that were outlined by the Brambell Committee in the United Kingdom in 1965 (Webster, 2001). These freedoms include (1) freedom from hunger and thirst - by ready access to fresh water and a diet to maintain full health and vigor; (2) freedom from discomfort-by providing an appropriate environment including shelter and a comfortable resting area; (3) freedom from pain, injury, or disease - by prevention or rapid diagnosis and treatment; (4) freedom to express normal behavior - by providing sufficient space, proper facilities, and company of the animal's own kind; (5) freedom from fear and distress - by ensuring conditions and treatment that avoid mental suffering (Webster, 2001).

The Five Freedoms serve as the hallmark of many animal welfare initiatives in the United States and beyond. They correspond to the 3 dimensions of welfare highlighted by Fraser et al. (1997) and thus provide a way to operationalize concern for animal welfare (Figure 1). They also encourage vigilance in our production systems so that farmed animals do not experience undue hardship. Although all of the freedoms are conceptually significant, different stakeholders in animal production may prioritize or value the various aspects of animal welfare delineated in the Five Freedoms differently. For example, farmers may think of welfare as being "good husbandry," which corresponds to ensuring freedom from malnourishment and from preventable disease and injury. Thus, believing that they already do a good job in this area, many farmers may see little need to alter their practices (Reisner, 1992). Conversely, an applied 


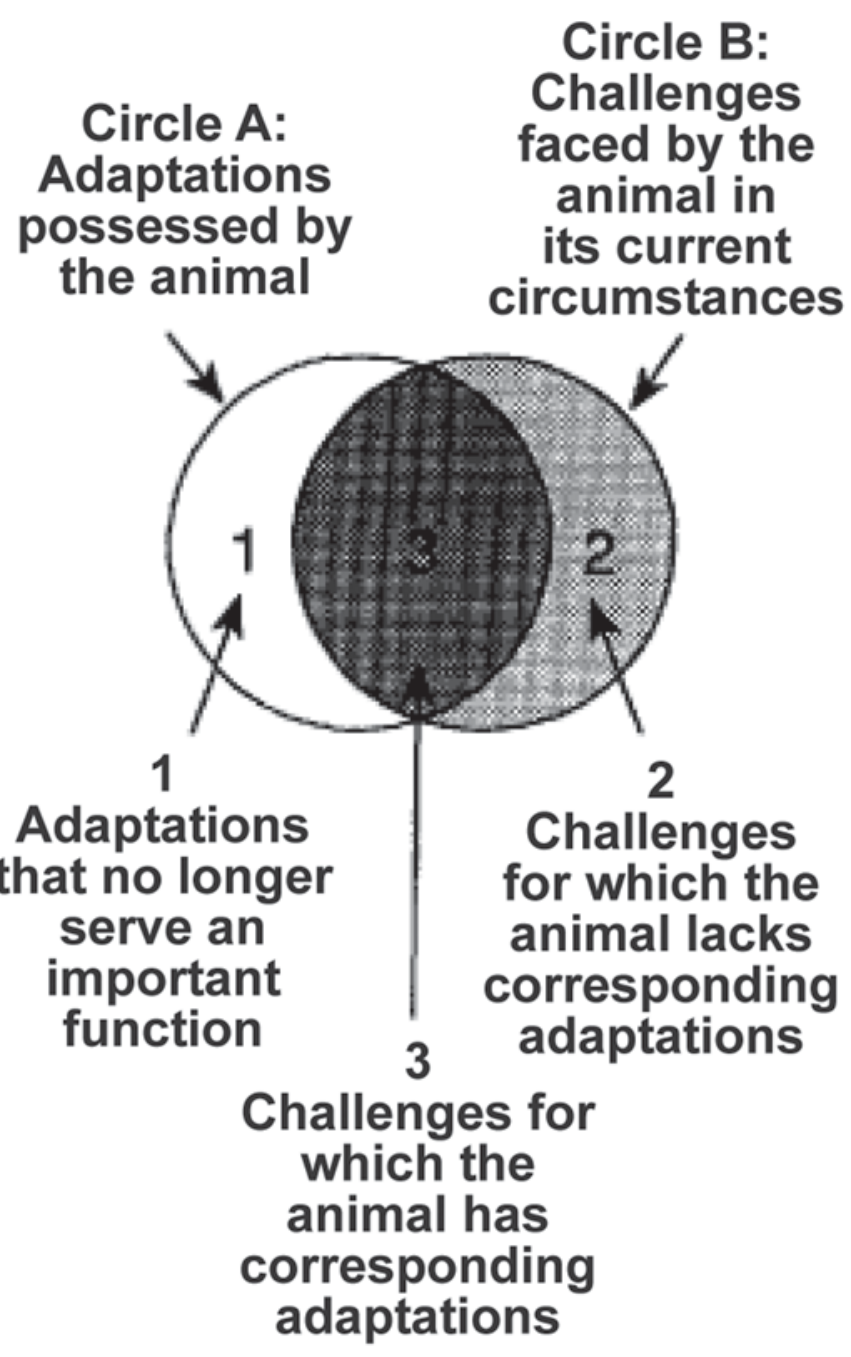

Figure 1. An integrative model conceptualizing 3 dimensions of animal welfare (Fraser et al., 1997). Animal welfare concerns correspond to different facets that constitute the quality of life of an animal. As Fraser et al. (1997) argue, failure to adequately address these facets will likely result in adaptations possessed by the animals (circle A) that make for an "imperfect fit" with challenges the animal confronts when kept in circumstances associated with production (circle B). Figure reproduced from Fraser et al. (1997) with permission from the Universities Federation of Animal Welfare (UFAW), Wheathampstead, Herts., UK.

ethologist may consider the feelings of animals to be the utmost priority (Duncan, 1996), whereas another member of that discipline may propose that welfare cannot be properly understood without encompassing animals' physical, mental, and behavioral health (Broom, 1988). Philosophers, on the other hand, may argue that good welfare requires that animals be allowed to live according to their "telos" or inherent natures (Rollin, 1995) or their evolutionarily inherited capacities (Nussbaum, 2004). This perspective is reminiscent of the freedom to engage in normal, species-typical behaviors or to not be behaviorally restricted without clear justification.
According to both Rollin and Nussbaum, animals have certain adaptations, inherited through the evolutionary process, that are suited for particular environments. As such, they flourish when they are allowed to perform behaviors for which they have adaptations, and this is not only important for their welfare, but is considered by many as a measure of respect (Fraser et al., 1997).

Regardless of which conception of welfare is chosen or which welfare criteria are prioritized, the challenge for contemporary dairy production is to clearly articulate what constitutes acceptable quality of life for dairy animals. Doing so requires being mindful that members of the public, who are also consumers, may have differing ideas on the subject, and that these should not be summarily dismissed as irrelevant or unimportant. To a large extent, producers and the concerned public alike are still confronted with some version of the following questions (Sandoe et al., 2003): "What is a good animal life? What is the relationship between dignity and welfare? What are acceptable compromises?"

It is also important to realize that although most consumers presume that farmers take good care of their animals (as in they meet the animals' needs for food, water and shelter), many are increasingly concerned that, especially in "industrialized" farming, insufficient care is given to the experience the animals are having or the quality of life they are living. In other words, perhaps there is too little focus on animals' affective states and too little priority given to the concept that they should be free to engage in normal behaviors. Media exposés depicting farm neglect, mistreatment, or outright animal abuse are therefore likely to heighten any latent concerns about farm animal care and welfare. Consequently, failure to address these issues provides public impetus to externally regulate the industry's practices as has been suggested previously by Rollin (2004).

Efforts to increase US farm animal welfare regulation have been underway for several years and have gained traction given the public's apparent concerns about the need to protect farm animals. For example, a 1995 Gallup poll showed that $91 \%$ of those surveyed disapproved of veal calf housing, and in $2003,62 \%$ supported passing strict laws governing farm animal treatment. More recently, a 2004 survey of Ohioans found that $75 \%$ of respondents agreed or strongly agreed that "farm animals should be protected from feeling physical pain" (Rauch and Sharp, 2005). Both collectively and on an individual basis, the American consumer is not only increasingly becoming more interested in the production history of their food, but is also concerned about ethical consumerism (see, for example, Singer and Mason, 2006).

Not only do Americans apparently have concerns about farm animal well-being, when they are in a posi- 
tion to act on their concerns via the voting booth, they tend to do so even when their purchasing behavior fails to reflect their purported beliefs (Appleby, 2005; Tonsor and Wolf, 2010). For instance, in November 2006, voters overwhelmingly supported animal welfare measures that appeared on state ballots, often with approval rates of $60 \%$ or higher. Voters in California passed Proposition 2 in 2008, which regulated the housing of gestating sows, egg laying hens, and veal calves. In 2009, Ohio's Issue 2, which proposed the development of a Livestock Care Standards Board to provide oversight of farm animal care practices, was also strongly supported (Tonsor and Wolf, 2010).

These activities would seem to suggest growing public demand for animal welfare assurance. They also indicate a general lack of trust in industry self-regulation and the need for US animal industries to more demonstrably address animal welfare. Despite animal welfare assurance programs devised by food industry retailers, processors, producer groups, and private organizations (Mench, 2003; Swanson, 2008), many appear to believe that external regulation is still needed.

As legislation of animal production practices continues to unfold differently in states across the United States, it is possible that the stage is being set for federal legislation of farm animal welfare standards that exceed those outlined by the Animal Welfare Act. Thus, as an essential step toward retaining their autonomy, the dairy industries need a coherent plan to address both the scientific and ethical issues that are fundamental to all animal welfare concerns, beginning with a critical assessment of its accepted practices. Some recent initiatives are already underfoot to begin addressing the ethical and social concerns related to animal welfare. These include voluntary principles, guidelines and welfare standards produced by industry organizations such as the producer-led (2008) National Dairy Animal Well-Being Initiative to "protect consumer trust and confidence in the dairy industry," programs employed by retail and restaurant companies that are members of the Food Marketing Institute and National Council of Chain Restaurants (Mench, 2003; Croney and Millman, 2007; Swanson, 2008). In addition, several intergovernmental agreements and international treaties exist, such as those created by the United Nations Food and Agriculture Organization and the World Organization for Animal Health (OIE).

\section{CRITICALLY EVALUATING THE IMPLICATIONS OF CONTEMPORARY DAIRY PRODUCTION PRACTICES}

Among the welfare issues facing the US dairy industry are housing and cow comfort, early separation of calves from their dams, transportation and health status of young male calves, as well as procedures and conditions that are considered to be painful, such as dehorning, lameness and mastitis. Lameness is among the most serious and costly welfare problems in dairy production, but studies show that the ability of herd managers to detect prevalence of clinical lameness, especially before the condition becomes advanced, is relatively low (Wells et al., 1993; Whay et al., 2003; Espejo et al., 2006; von Keyserlingk et al., 2009). Clearly, unnecessary pain and suffering associated with failure to detect and treat lame cows is a welfare issue that also poses an economic problem for farmers forced to cull lame cows at high rates.

Likewise, mastitis is a costly disease affecting the dairy industry that also has implications for animal pain and suffering and raises the broader question of cow longevity in contemporary production. In the United States, a survey of dairy producers revealed that $26.9 \%$ of all dairy cows culled were culled for udder health or mastitis problems, and mastitis was also one of the leading causes of mature cow deaths (USDA, 2002). Furthermore, clinical mastitis was identified as the most prevalent of all diseases, with $14.7 \%$ of all dairy cows experiencing mastitis in the previous year. Barkema et al. (1998) have reported findings of more than $25 \%$ of cows suffering from clinical mastitis annually in well-managed herds.

Handling, transportation, and slaughter are important areas of concern. For example, handling of cattle (especially of nonambulatory animals) is a key factor in their well-being. Research in various animal industries, including the dairy industry, has demonstrated the profound effect of human-animal interactions on animal behavior, productivity, and welfare (Hemsworth and Coleman, 1998). Use of behaviors by animal handlers that cause dairy cattle to become highly fearful of humans can lead to animals being difficult to handle, move, and milk; can increase the risk of injury to both animals and handlers; and can contribute to a reduction in milk yield and overall poor animal welfare.

However, the importance of the animal caretaker in influencing animal productivity and welfare and the need to properly train animal handlers has often been overlooked. This raises both ethical as well as practical (economic) issues. No incident better illustrates this point than the scandal that occurred in 2008 at the Westland Hallmark processing plant in California, which resulted in the largest meat recall in US history (143 million pounds of beef). Inappropriate preslaughter handling of nonambulatory dairy cows - that extended, in several instances, to outright abuse of the animalswas observed as workers attempted to get the cows to enter the facility. Not only was public concern heightened relative to animal welfare, debate escalated about 
the food safety implications of inhumane and improper animal treatment and the need for further regulation and enforcement of laws pertaining to this segment of animal production. Thus, from both a scientific and an ethical perspective, the justification for improved dairy animal handling is clear.

Other welfare issues relating to contemporary dairy production are even more troublesome. Because it would be impossible to adequately address all of them in one paper, the remainder of this analysis will focus on two of the most immediately problematic dairy welfare issues; namely, pain relief and tail docking in dairy cattle.

\section{Pain Relief}

Relief of pain in dairy cattle is a contentious issue that has both scientific and ethical implications for animal welfare. For example, the use of analgesic drugs to treat pain associated with mastitis is still very limited. However, the treatment of pain in farm animals is important not only on ethical and moral grounds, but also because of the potential negative consequences for animal productivity. Changes in behavior, such as reduced feed intake, and immunosuppression due to prolonged stress associated with mastitis and other painful conditions can adversely affect milk production and susceptibility to infection. Moreover, McDougall et al. (2009) reported that treatment of cows with clinical mastitis with a combination of nonsteroidal antiinflammatory drugs and antibiotics resulted in a lower somatic cell count and a reduced risk of removal from the herd (culling) compared with treatment with antibiotic alone.

Nonetheless, the use of analgesics in dairy production remains limited, partly because of the time and cost associated with using these drugs, and also because very few drugs are approved for use in lactating cows. Complicating matters is the finding that a veterinarian's subjective perception of pain in cattle may affect whether or not he or she even attempts to mitigate painful conditions in cows. For instance, Fitzpatrick et al. (2002) asked veterinary surgeons with expertise in cattle practice about their perceptions of pain for several common cattle procedures and diseases. Lameness was considered more painful than either mastitis or cesarean section. Yet, provision of analgesics for cattle experiencing any of these conditions remains uncommon in the United States (Fitzpatrick et al., 2002).

Clearly, ethical issues arise if veterinarians and others improperly assess the need to alleviate pain in cattle that are actually experiencing significant pain or choose not to address it solely for financial expediency. Moreover, an obvious ethical question that arises is whether given the evidence that pain (or poorer welfare) is associated with mastitis, industry agents and producers should not do more to alleviate this (and any other) painful conditions than is currently the case. Additionally, more nuanced ethical concerns arise that pertain to the extent to which it is acceptable to rear cows under circumstances that permit the development of painful conditions such as mastitis and lameness that are likely to be left untreated and that reduce not only the animal's longevity, but also her overall well-being.

\section{Tail Docking}

Tail docking of cows is often used in US dairy production and the practice was adopted in an effort to improve milk hygiene, udder cleanliness, and health, and to promote milker comfort, health, and hygiene. However, tail docking raises both ethical and scientific concerns. First, the obvious alteration to the cows may be viewed negatively by members of the public who are concerned about causing unnecessary pain to animals and about impairing normal cow behavior, such as fly deterrence. Second, it is difficult to justify the practice scientifically because debate exists about whether docking causes chronic pain to the cow (Eicher et al., 2006; von Keyserlingk et al., 2009), and despite the rationale for docking, no differences have been observed in milk production or milk hygiene in docked cows. However, higher fly loads on docked cows have been noted (Ladewig and Matthews, 1992; Matthews et al., 1995; Eicher et al., 2001; Tucker et al., 2001; Eicher and Dailey, 2002; Schreiner and Ruegg, 2002; von Keyserlingk et al., 2009). Thus, the scientific justification originally offered to support the practice is questionable, which is problematic for any industry that must operate from a sound scientific basis. Also, the main benefit of docking seems to be worker comfort, which could be achieved less invasively - either by improved management of the cow's environment or by trimming only the hairy switch of the tail.

Despite this information and the possibility that tail docking may not be well accepted by the public, many industry members continue to support tail docking. This approach would seem to be short-sighted, given that although most people have minimal knowledge about farming, many believe that animals are sentient and feel pain, and have a vested interest in how they are treated. Combine this with the "Disney factor"the ubiquitous anthropomorphic portrayals of animals (Jamison and Lunch, 1992) perpetuated by some of the industry's own commercials (Croney and Reynnells, 2008) - and the increasingly popular sentiment that large-scale, intensive farming disregards the experiences of animals, and it would seem obvious that this sort of 
decision-making might fail the test of transparency or moral responsibility, thus, encouraging external oversight and regulation.

In summary, the ethical questions surrounding tail docking include the following: (1) Is the practice justifiable? (2) Is the harm done to the cow outweighed by the benefits to milkers? (3) Are there viable, ethically sound alternatives to the practice? Concern for the welfare of the dairy cow in this instance suggests that the industry must review and revise practices that are not well supported by science, and which may raise some ethical questions among some consumers and farmers. An organized process that permits ethical analysis and scientific assessment of the merits of the respective positions on such a contentious issue may prove helpful and, from an ethical point of view, may be essential.

\section{ETHICAL ACCOUNTING AND ANIMAL WELFARE}

As the above discussion suggests, there is little disagreement regarding the obvious practices that entail unnecessary pain and suffering on the farm. However, little consensus exists regarding the more nuanced practices that appear to be necessary and that conventional animal agriculture has adopted as part of "standard industry practices." Animal welfare assessment or accountability tools can help those "in the trenches" and consumers at large make appropriate ethical choices in conjunction with the empirical observations about how certain production practices affect farm animals directly.

Campbell's Ethics Assessment Process (Croney and Anthony, 2010) offers one means by which to objectively analyze ethical dilemmas that are often encountered in farm animal production. Another aid is the "Ethical Matrix" (Figure 2), which was devised by researchers at the University of Nottingham (Mepham, 2000). The Matrix begins with the assumption that common morality provides sufficient grounds for framing and addressing ethical issues in animal agriculture, and that good empirical observations should inform the practical recommendations we make on the farm and as part of public policy. The Matrix, like other ethics assessment instruments, promotes methodical and critical ethical decision-making by inviting reflective deliberation, and it was designed to be used openly to include the interests of a spectrum of stakeholders. The Matrix turns to key elements of our common morality as the starting point of ethical deliberation. These include respect for well-being, respect for choice and decision-making capacity, and respect for fairness (Mepham, 2000; Croney and Anthony, 2010). The Matrix can be employed when science alone cannot provide reliable answers to important welfare concerns and when different stake- holder interests are in play. This reconstruction of the Matrix (Figure 2) 9 individual cells that correspond to principles of respect that are based on our common morality (welfare, choice, and fairness). These cells correspond to the interests of some key stakeholders; that is, farmers, consumers, and farm animals. Users of the Matrix are meant to score (e.g., on a scale of -3 to +3 ) the effects they think a selected system of animal production or particular practice will have on the ethical principles. The conclusions drawn may then provide guidance when a high degree of moral and scientific uncertainty exists.

One benefit of an accounting tool such as the Ethical Matrix is that it helps us identify our normative commitments as they apply to animal welfare. These normative commitments depend on the relative weight we give to the benefits and harms that animals can experience and to understanding their natures. It also forces us to reflect on the values that (should) make up best practices when animal use is concerned. In considering the issue of tail docking, for example, the Ethical Matrix spotlights several considerations that can help to advance the discussion regarding best practices. All things considered (and suspending economic reasons for the moment), the matrix helps us to see that for some stakeholders, the pain and suffering that the docked animals may experience (consequentialist evaluation) is a primary issue. For others, it may be the ability of the animals to perform natural behaviors (a rights-based or justice-based evaluation). For some, human convenience may be more important (a human-centered welfare evaluation). Upon identifying the different interests, and as part of an open and democratic dialog on what is good for animals, people, and the environment, welfare assessment tools such as the matrix and Campbell's Ethics Assessment Process afford users the opportunity to reconsider their normative commitments to the relative weight given to basic and peripheral interests as they relate to human and nonhuman animal species. Going back to the case above, a strong case for continuing the practice of tail docking from an animal welfare perspective has not been made by the dairy industry. By following the argument that is composed of both empirical and moral premises to its logical conclusion, if the negative effects on cows are deemed greater than the relative benefits to humans, the moral orientations that seek to maximize good consequences over bad ones for all stakeholders, and which appeal to fairness, would indicate that the practice of tail docking dairy cattle should be terminated.

A similar accounting of practices and consideration of the relative weights given to human and animal welfare concerns can be applied to other on-farm animal welfare issues such as access to pasture and the most 


\begin{tabular}{|l|l|l|l|}
\hline Respect for & Welfare & Choice & Fairness \\
\hline $\begin{array}{l}\text { Farmers and others } \\
\text { in the food industry }\end{array}$ & $\begin{array}{l}\text { Satisfactory income } \\
\text { and workplace }\end{array}$ & $\begin{array}{l}\text { Managerial freedom } \\
\text { and professional } \\
\text { responsibility }\end{array}$ & $\begin{array}{l}\text { Current laws, } \\
\text { guidelines and } \\
\text { regulation }\end{array}$ \\
\hline Consumers & $\begin{array}{l}\text { Food safety and } \\
\text { quality }\end{array}$ & $\begin{array}{l}\text { Informed decision- } \\
\text { making }\end{array}$ & $\begin{array}{l}\text { Affordability and } \\
\text { availability }\end{array}$ \\
\hline Farmed animals & $\begin{array}{l}\text { Feel well and } \\
\text { function well }\end{array}$ & Behavioral freedom & $\begin{array}{l}\text { Intrinsic value and } \\
\text { respectful treatment }\end{array}$ \\
\hline
\end{tabular}

Figure 2. The Ethical Matrix offers a structured way of working through animal welfare concerns. This interpretation is an adaptation; it is meant only as an example and by no means provides an exhaustive list of stakeholders or their interests nor does it score an outcome. Please refer to http://www.nottingham.ac.uk/bioethics/theory_pages/matrix.htm for a more detailed discussion of the matrix, including limitations regarding its use.

acceptable pain management regimen for each farming condition.

\section{SUMMARY}

Because of the diversity of perceptions of what constitutes acceptable quality of life for farm animals, today's production practices and standards cannot responsibly be determined by individual preferences and other unclear premises. Instead, a transparent means of establishing welfare standards for dairy animals that is exemplified in ethical accounting and assessment tools such as the Ethical Matrix may be required to promote trust and confidence in animal agriculture as consumers become more concerned about what they eat and more knowledgeable about the production history of their food (Singer and Mason, 2006).

As indicated previously, industry, the public, and government stakeholders all desire that positive steps be taken to improve the sustainability of our food production system. This means better governance or oversight of production practices as well as reflection of individual and collective consumption habits. The link between ethics and science is therefore important to help address the issues above. Not only is it necessary that improvements and changes to production practices are motivated by careful scientific analysis, it is also important to consider how the scientific premises employed to justify these practices are incorporated in ethical arguments.

It therefore becomes increasingly clear that the dairy industry must move beyond the comfort zone of scientific and economic discussions about dairy cow production to consider and clearly state how cows should be treated. In other words, the industry must make the ethical case for contemporary dairy production and define the ethical parameters for its operations. Unfortunately, for those used to dealing purely with science, this can be exceptionally challenging. However, as dairy production practices continue to be challenged on ethical grounds, it becomes important to understand the constraints of science in addressing these sorts of concerns. Science, for instance, can answer the question of what risks are associated with certain practices, or what the effects may be of feeding or housing dairy cows in certain ways. However, science cannot determine whether it is right or even socially acceptable to adopt certain practices or assume the risks that may be associated with them (Wandersman and Hallman, 1993; Swanson, 2003). The latter are inherently normative issues or in some cases are conditionally normative, if the relevant research is still underway (Brunk et al., 1991). Thus, decisions about how we ought to treat animals may be influenced or informed by science, but cannot be dictated solely by it because of the normative nature of animal welfare.

As the US dairy industry faces the challenge of critically analyzing its practices, a clearly articulated ethic of care and compassion for animals is needed to engage public concerns. This presents a formidable challenge, but as we have attempted to highlight above with the ethical assessment and accounting matrices, animal scientists have help from ethics tools developed just for this purpose. Utilizing these will likely afford the industry the chance to better meet changing societal perceptions, expectations, and values relating to animal quality of life, thus giving it a better chance of maintaining public support.

\section{REFERENCES}

Anthony, R. 2003. Ethical implications of the human-animal bond on the farm. Anim. Welf. 12:505-512.

Appleby, M. C. 2005. The relationship between food prices and animal welfare. J. Anim. Sci. 83(E. Suppl.):E9-E12.

Baier, A. C. 1986. Trust and antitrust. Ethics 96:231-260.

Barkema, H. W., Y. H. Schukken, T. J. G. M. Lam, M. L. Beiboer, H. Wilmink, G. Benedictus, and A. Brand. 1998. Incidence of clinical 
mastitis in dairy herds grouped in three categories by bulk milk somatic cell counts. J. Dairy Sci. 81:411-419.

Broom, D. M. 1988. The scientific assessment of animal welfare. Appl. Anim. Behav. Sci. 20:5-19.

Brunk, C., L. Haworth, and B. Lee. 1991. Value Assumptions in Risk Assessment: The Alachor Controversy. WLU Press, Waterloo, ON, Canada.

Croney, C. C., and R. Anthony. 2010. Engaging science in a climate of values: Tools for animal scientists tasked with addressing ethical problems. J. Anim. Sci. 88(E. Suppl.):E75-E81.

Croney, C. C., and S. T. Millman. 2007. Board-Invited Review: The ethical and behavioral bases for farm animal welfare legislation. J. Anim. Sci. 85:556-565.

Croney, C. C., and R. D. Reynnells. 2008. The ethics of semantics: Do we clarify or obfuscate reality to influence perceptions of farm animal production? Poult. Sci. 87:387-391.

Duncan, I. J. H. 1996. Animal welfare defined in terms of feelings. Acta Agric. Scand. A Anim. Sci. Suppl. 2:29-35.

Eicher, S. D., H. W. Cheng, A. D. Sorrells, and M. M. Schutz. 2006. Short communication: Behavioral and physiological indicators of sensitivity or chronic pain following tail docking. J. Dairy Sci. 89:3047-3051.

Eicher, S. D., and J. W. Dailey. 2002. Indicators of acute pain and fly avoidance behaviors in Holstein calves following tail-docking. J. Dairy Sci. 85:2850-2858.

Eicher, S. D., J. L. Morrow-Tesch, and J. L. Albright. 2001. Tail-docking alters fly numbers, fly-avoidance behaviors, and cleanliness, but not physiological measures. J. Dairy Sci. 84:1822-1828.

Espejo, L. A., M. I. Endres, and J. A. Salfer. 2006. Prevalence of lameness in high-producing Holstein cows housed in freestall barns in Minnesota. J. Dairy Sci. 89:3052-3058.

Fitzpatrick, J. L., A. M. Nolan, E. M. Scott, L. S. Harkins, and D. C. Barrett. 2002. Observers perceptions of pain in cattle. Cattle Pract. 10:209-212.

Fraser, D., D. M. Weary, E. A. Pajor, and B. N. Milligan. 1997. A scientific conception of animal welfare that reflects ethical concerns. Anim. Welf. 6:187-205.

Glenn, C. B. 2004. Constructing consumables and consent: A critical analysis of factory farm industry discourse. J. Commun. Inq. $28: 63-81$.

Harper, G. C., and A. Makatouni. 2002. Consumer perception of organic food production and farm animal welfare. Br. Food J. 104:287-299.

Haynes, R. 2008. Animal Welfare: Competing Conceptions and Their Ethical Implications. Springer, Dordrecht, the Netherlands.

Hemsworth, P. H., and G. J. Coleman. 1998. Human-Livestock Interactions: The Stockperson and the Productivity and Welfare of Intensively Farmed Animals. CAB International, Wallingford, UK.

Jamison, W. V., and W. M. Lunch. 1992. Rights of animals, perceptions of science, and political activism: Profile of American animal rights activists. Sci. Technol. Human Values 17:438-458.

Ladewig, J., and L. R. Matthews. 1992. The importance of physiological measurements in farm animal stress research. Proc. N.Z. Soc. Anim. Prod. 52:77-79.

Matthews, L. R., A. Phipps, G. A. Verkerk, D. Hart, J. N. Crockford, J. F. Carragher, and R. G. Harcourt. 1995. The effects of taildocking and trimming on milker comfort and dairy cattle health, welfare and production. Animal Behaviour and Welfare Research Centre, Hamilton, New Zealand.

McDougall, S., M. A. Bryan, and R. M. Tiddy. 2009. Effect of treatment with the nonsteroidal anti-inflammatory meloxicam on milk production, somatic cell count, probablility of re-treatment, and culling of dairy cows with milk clinical mastitis. J. Dairy Sci. 92:4421-4431.
Mench, J. A. 2003. Assessing animal welfare at the farm and group level: A United States perspective. Anim. Welf. 12:493-504.

Mepham, B. 2000. A framework for the ethical analysis of novel foods: The ethical matrix. J. Agric. Environ. Ethics 12:165-176.

Nussbaum, M. 2004. Beyond 'compassion and humanity': Justice for nonhuman animals. Pages 299-320 in Animal Rights: Current Debates and New Directions. Cass R. Sunstein and Martha C. Nusbaum, ed. Oxford University Press, Oxford, UK.

Rauch. A., and J. S. Sharp. 2005. Ohioans' Attitudes about Animal Welfare. A topical report from the 2004 Ohio Survey of Food, Agricultural and Environmental Issues. Department of Human and Community Resource Development, The Ohio State University, Columbus.

Reisner, A. 1992. An activist press: The farm press's coverage of the animal rights movement. Agric. Human Values 9:38-53.

Rollin, B. E. 1995. Farm Animal Welfare: Social, Bioethical and Research Issues. Iowa University Press, Ames.

Rollin, B. E. 2004. Animal agriculture and emerging social ethic for animals. J. Anim. Sci. 82:955-964.

Sandoe, P. S. B. Christiansen, and M. C. Appleby. 2003. Farm animal welfare: the interaction of ethical questions and animal welfare science . Anim. Welf. 12:469-478.

Schreiner, D. A., and P. L. Ruegg. 2002. Effects of tail docking on milk quality and cow cleanliness. J. Dairy Sci. 85:2503-2511.

Singer, P., and J. Mason. 2006. The Ethics of What We Eat: Why our Food Choices Matter. Rodale Inc./Holtzbrinck Publishers, New York, NY.

Swanson, J. C. 2008. The ethical aspects of regulating production. Poult. Sci. 87:373-379.

Swanson, J. C. 2003. Farm Animal Welfare Assurance: Scientific and Retailer Perspectives. Proceedings of the 6th Western Dairy Management Conference. Accessed Jun. 20, 2009. http://www.wdmc. org/2003/Farm Animal Welfare Assurance-Scientific and Retailer Persp.pdf.

Thompson, P. B. 1998. Agricultural Ethics: Research, Teaching, and Public Policy. Iowa State University Press, Ames.

Tonsor, G. T., and C. A. Wolf. 2010. Drivers of resident support for animal care oriented ballot initiatives. J. Agric. Appl. Econ. 42:419-428.

Tucker, C. B., D. Fraser, and D. M. Weary. 2001. Tail docking dairy cattle: Effects on cow cleanliness and udder health. J. Dairy Sci. 84:84-87.

USDA. 2002. Part I: Reference of Dairy Health and Management in the United States, 2002. USDA:APHIS:VS:CEAH. \#N377.1202. National Animal Health Monitoring System, Fort Collins, CO.

von Keyserlingk, M. A. G., J. Rushen, A. M. de Passillé, and D. M. Weary. 2009. Invited review: The welfare of dairy cattle - Key concepts and the role of science. J. Dairy Sci. 92:4101-4111.

Wandersman, A. H., and W. K. Hallman. 1993. Are people acting irrationally? Understanding public concerns about environmental threats. Am. Psychol. 48:681-686.

Webster, A. J. F. 2001. Farm animal welfare: The five freedoms and the free market. Vet. J. 161:229-237.

Wells, S. J., A. M. Trent, W. E. Marsh, and R. A. Robinson. 1993 Prevalence and severity of lameness in lactating dairy cows in a sample of Minnesota and Wisconsin herds. J. Am. Vet. Med. Assoc. $202: 78-82$

Whay, H. R., D. C. Main, L. E. Green, and A. J. Webster. 2003. Assessment of the welfare of dairy cattle using animal-based measurements: Direct observations and investigation of farm records. Vet. Rec. 153:197-202. 